\title{
Efficacy of Sensory Integration Therapy in Improving Gross Motor Coordination and Grip Control in Down Syndrome Children
}

\author{
Ahmed M. Azzam \\ Department of Physiotherapy for Developmental Disturbance and Pediatric Surgery, Faculty of Physical Therapy, Cairo \\ University, Giza, Egypt \\ Email: pr.ahmedmetwally@hotmail.com
}

How to cite this paper: Azzam, A.M. (2019) Efficacy of Sensory Integration Therapy in Improving Gross Motor Coordination and Grip Control in Down Syndrome Children. World Journal of Neuroscience, 9, 23-38.

https://doi.org/10.4236/wjns.2019.92002

Received: February 25, 2019

Accepted: May 6, 2019

Published: May 9, 2019

Copyright $\odot 2019$ by author(s) and Scientific Research Publishing Inc. This work is licensed under the Creative Commons Attribution International License (CC BY 4.0).

http://creativecommons.org/licenses/by/4.0/

\begin{abstract}
This work was carried out to investigate the efficacy of sensory integration therapy in improving gross motor coordination and grip control in Down syndrome children. Thirty children were enrolled in this study and randomly assigned into two groups: group A received (sensory integration therapy program plus specific physiotherapy training) and group B received (specific physiotherapy training program only). Motor coordination test measures (Balancing backward, Hopping, Jumping from side to side and Transferring boxes) to test and follow gross motor coordination, handheld dynamometer to test and follow grip control ability and kinesthesia test to test and follow awareness of joint position and movement. These measurements were taken before initial treatment and after 12 weeks of treatment. The children parents in both groups A and B were instructed to complete 3 hours of the home routine program. Data analysis was available on the 30 Down syndrome children participating in the study. The difference between pre- and post-treatment results was more significant in Motor coordination test measures in the study group than the control group. Grip control ability and kinesthesia test demonstrate representative improvement in the study groups $(\mathrm{p}=0.0001)$ while insignificant in the kinesthesia control group and significant in a grip control group. The addition of sensory integration therapy program to specific physiotherapy training is recommended in improving gross motor coordination and grip control abilities in Down syndrome, so this suggested approach may be used as a selective choice for improving posture control and hand functions in Down syndrome children.
\end{abstract}

\section{Keywords}

Sensory Integration Therapy, Gross Motor Coordination, Hand Grip, 
Down Syndrome

\section{Introduction}

The responsibility of overexpression genes present in chromosome 21 on occurring central nervous system dysfunctions in Down syndrome children is the decrease of amount, shape and volume of the neurons, impaired neural myelination of CNS, insufficient neurotransmitter, degenerative process and more expressions of neural apoptosis and amyloidal precursor protein [1] [2].

Several factors cause the delay in gross motor coordination in Down syndrome, firstly hypotonic factor which affects abdominal muscles resulting in loss of balance during standing. The second is the laxity of the ligament due to abnormal collagen distributions appearing in foot leading to flat feet, in knee leading to genu recurvatum and in hip leading to hypermobility with instability of the joint. The third is the decreased muscle strength especially trunk muscles and LL muscles which interfere with skills development and the last factor is the shortening of the limbs in relation to trunk length leading to difficulty in acquiring sitting unless the child flexes his trunk forward to be able to use upper limbs as a support and move farther sideways when he has fallen to the side to compensate the arm shortening also he has difficulty in climbing stairs due to its height in relation to shorted L. L. [3].

The brain of DS children becomes smaller and lighter than normal children, decreased neuronal numbers, impaired synaptic efficiency due to decreased neurotransmitter and delayed in the neural myelination process. The central nervous system provides a solution to these problems by producing an abnormal co-contraction pattern of pre-programmed movement to increase balance response leading to increasing effects of disturbances. This will lead to walking, grasping and reaching becoming slower in reaction time [4].

There are delaying stages of motor development in Down syndrome; this slowness in gross and fine motor abilities affects neuropsychomotor abilities [5]. As well as decreased bone density, cartilage hypoplasia, laxity of ligaments and hypotonia affect joint torque and contraction efficiency leading to impaired ADL activities and postural reaction [6].

In Down syndrome, there is a delay of motor control and sensory feedback leading to physical, cognitive and perceptual limitations which interfere with ADL activities [7] [8] [9]. Long motor reaction time is the most problem facing Down syndrome in performing functional motor skills, programming, and fractionated reaction, leading to high energy consumption and clumsy gross and fine motor skills [10].

According to the proximal-distal development principle, trunk stability is developed first and is considered a pre-request to fine motor skills [11]. The motor learning process is the main core based on the treatment of DS because it depends on the improvement of perception-cognition complex that is the base of motor control which is delayed in DS [12]. 


\section{Materials and Methods}

\subsection{Demography}

30 children from the two sexes with Down syndrome children were joined in this study at Private Schools for Down syndrome, aged 6 to 9 years at a time of enrollment due to the children in this age could participate in gross motor coordination graduations. Children could walk with assistance, otherwise, DS that run up against the involvement rules were derived out if they had: preceding amputation surgery in the L. L., sever convulsion and advanced mental delay

\subsection{Sample Collection}

Children were selected randomly to the study group (A) taken sensory integration therapy (SIT) plus specific physiotherapy program at the same time the control group (B) taken specific physiotherapy program only. The individual-based SIT treatment sessions of 60 minutes plus specific physiotherapy program for 60 minutes were conducted 7 days a week for 3 months in a physiotherapy treatment room for the group (A). Also, children in the study and control groups were subjected to home regular program 3 hours daily for the 3 months treatment period. The control group (B) received a specific physiotherapy program only.

\subsection{Outcome Measurements}

1) Gross motor coordination: Via Motor coordination test measures. It consists of four items:

a) Posture stability evaluation by using balancing backward test, balance bar was used by asking the child to walk backward alongside the bar to test them. Numbers of successful steps were recorded.

b) Coordination and motor control evaluation: by using Hopping test: foam squares were used by asking the child to jump on foam square and with advance the test more foam placed over each other. Numbers of foam square in the last jump were recorded.

c) Jumping from side to side by using small beam. The children asked to jump in side way within 15 seconds. A number of corrected jump were recorded.

d) Motor planning and organization evaluation by using transferring boxes: to test by using 2 boxes. The child hold one box in his hand and step over the other then put the box in his hand alongside the other to step on it with lifting the other box. A number of corrected movements were recorded [13].

2) Grip control assessment: By hand-held dynamometer used to test skeletal musculature development in DS. The child was seated with elbow level at the same level of a table or slightly above with shoulder adducted to the trunk and elbow flexed 90 degrees. Three repetitions were performed and the best performance one was recorded [14].

3) Kinesthesia task assessment: To test awareness of body position and movement by asking the child to close his eyes with holding his fingers to move 
it from a predetermined point to another on the sheet then ask the child to repeat this movement based on his sense of movement. Measurement the distance between a predetermined point and the point which the child reached [15].

\subsection{Intervention}

For all children, the treatment was handling 7 days a week, for 3 months. Each session persists for 120 minutes (60 minutes sensory integration therapy program for study group plus 60 minutes for specific physiotherapy program for each group) in a physical therapy room, in addition to 3 hours of the home regular program, 7 days a week around the treatment period.

Physical problems in Down syndrome:

1) Hypotonia

Affects the gross and fine motor skills.

2) Loose joints and ligaments

3) Hand formation (functions)

- Hands are smaller, fingers shorter and thumb directed down these abnormal hand structure affect on hand functions

4) Impaired balance and postural stability

5) Delayed milestone

6) Learning problems

7) Slow movement due to delayed reaction time and motor performance

8) Abnormal clumsy gait due to wrong co-contraction and preprogramming response

Both groups (A and B) received specific physiotherapy training program like the following:

1) Hand function training through locating the level of hand grade and training this level till be well developed to transmit the next level according to 8 parameters (size-shape-weight-texture of material-reaction time-speed-accuracy-number of trials).

2) Balance training through the facilitation of postural reaction.

3) ADL activities training (feeding training-dressing training-toileting training).

4) Functional skills training through walking in (sand walking, weight on legs, swimming training and climbing stairs).

5) Cognitive skills training (problems solving tasks).

6) Improve active participation by up see therapy by open the closed home environment to facilitate walking and standing actively.

7) Coordination ex. by using a finger to finger, finger to nose, heel to knee and make circle and figure of 8 by legs start slow then fast and with the opened eye then closed eye.

8) Communication and social skills training.

9) Improve joint stability by improving co-contraction, posture control and graduated active ex.

10) Daily exposure to sunlight for activation of Vit. D which is severely diminished in DS. 
11) Proper standing posture training through standing with disturbance, against the wall, against stand bar with shifting and change BOS and disturbance plus standing with holding on.

12) Gait training: walk with wide base gait due to hypotonia, ligament laxity and muscle weakness training aiming to decrease BOS during walking.

13) Trunk posture training: upright posture training during sitting with graduated active ex. to trunk muscles to correct (abnormal sitting posture, sit with a backward pelvic tilt, curved trunk and the head lying down on the shoulders).

14) Facilitatory techniques as faradic stimulation to antigravity muscles, quick stretching, facilitate muscle contraction by (tactile stimulation-compression on bony prominence and rubbing on muscles).

15) Facilitation of delayed milestone [16].

The experimental group (group A) received sensory integration therapy program as following:

Sensory integration therapy is considered a bridge which Down syndrome children search for it to reach the optimum reaction time of motor control. The sensory integration therapy include tactile stimulation therapy which depends on stimulation of extroceptors which has protective and discrimination functions and proprioceptors stimulation therapy which receive the stimulations from muscles and joints which depend on push and pull activity and it is considered vital in development of fine and gross motor activity in Down syndrome because it affects on motor planning activities plus the vestibular stimulation therapy which depend on receiving the stimulus from movement and gravity affecting on balance, eye movement, posture, muscle tone, and attention [17].

Functional activities of tactile, proprioceptive and vestibular training:

1) Motor planning skills: -Throwing and catching balls of different size, shape, weight, and texture.

- Standing, walking, running, hopping and jumping on different surfaces (rubbery-rough-smooth-slippery).

2) Righting, equilibrium and protective reaction training from different positions.

- Quadripedal activities: as play boat in the ocean (disturbance and graduations).

- Appeal activities: as climbing stairs, pushing and pulling activities, carrying of heavy material, jumping, hopping, skipping and drawing.

3) Visual-spatial perception: puzzles training, block designs, a copy of designs, serial activities as graduated pegs and pegboard activities [18].

4) Postural stability training: by vestibular stimulation training (Figure 1 and Figure 2).

Selective sensory integration therapy:

1) Exteroceptive training:

- Using of different texture and heat surfaces with asking DS children to touch and deal with it by hands and by feet (rubbery, rough, smooth, slippery, steeping, crude and wool) with normal, warm, cold and heated surfaces. 


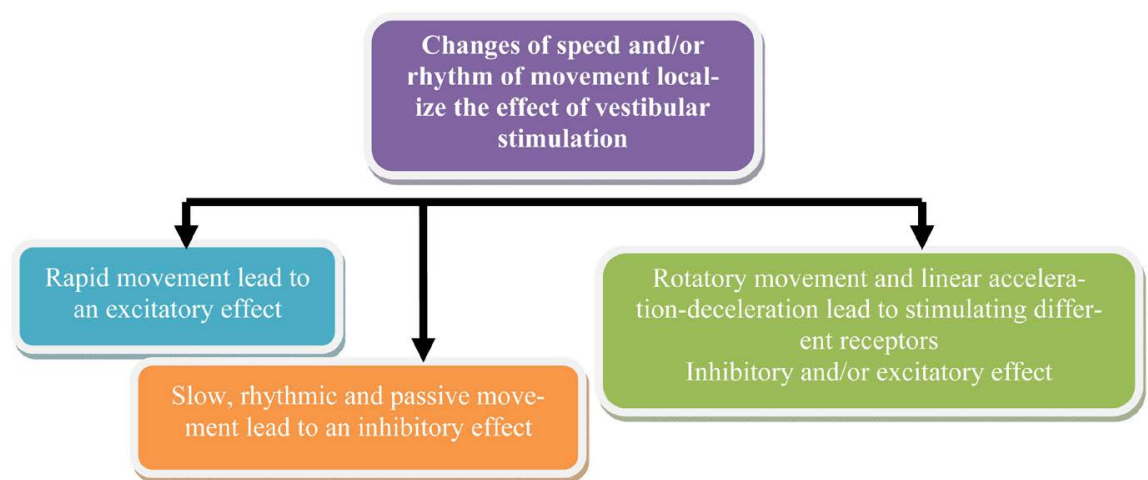

Figure 1. Effects vestibular stimulation according to speed and rhythm [19] [20].

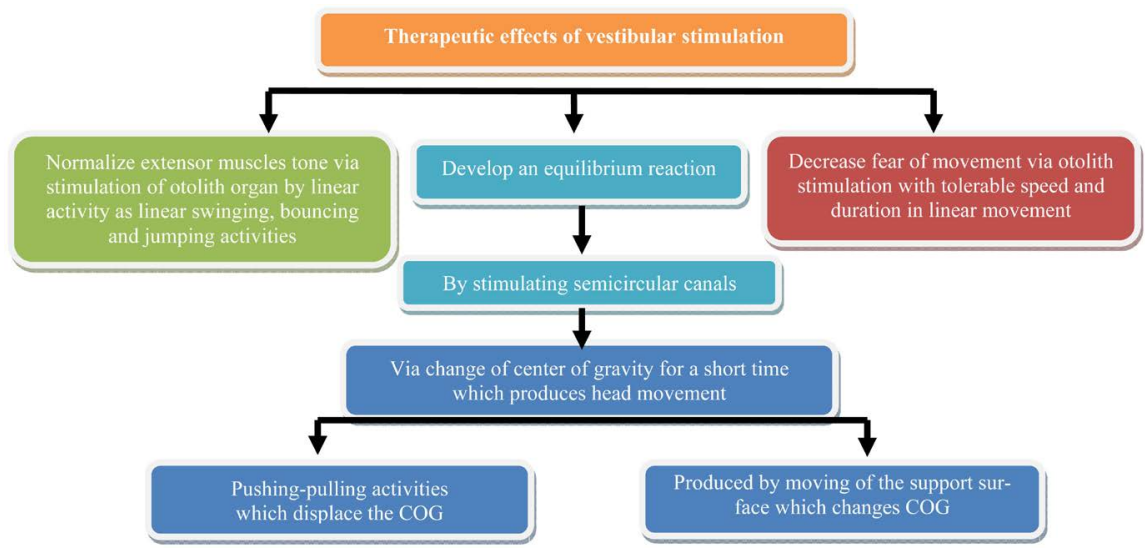

Figure 2. Therapeutic effects of vestibular stimulation therapy [21].

- Scratching, pressuring, raping, brushing and scrubbing the skin tactile receptors.

- Placing hands and feet in sands, beans, and rice for discrimination.

- Taste, smell, visual and hearing stimulation.

2) Vestibular training:

- Disturbance of the child from different developmental positions with changing of the base of support and center of gravity with eye opened then closed and with shifting weight on the two legs then on one leg to achieve gradual postural control ability.

- Upside down, swinging therapy, medical ball, balance board, and biodex stability system training.

- Gait training on one line then side walking then bypass walking.

3) Proprioceptive training:

- Static proprioceptive training via weight bearing and positioning.

- Dynamic proprioceptive training via walking and manual approximation in whole joint angles to stimulate whole proprioceptors of lower, upper limbs joints and shoulder and pelvic girdles.

- Weighted clothes were used for proprioceptive stimulation.

- Weighted ball for pulling and pushing was used for stimulation.

- Find the hide objects from a different material. 


\section{4) Cortical sense training:}

- Using of different material size, shape, weight, and texture with closed eyes for identifications and stereognosis skill training using one hand then the other.

- Using different letters and numbers with closed eyes for graphesthesia skill training using one hand then the other.

- Using double hand tactile with face tactile training for tactile extinction skill training [22].

\subsection{Statistical Analysis}

SPSS statistical package was used to calculate $\mathrm{p}$ value via dependent and independent $\mathrm{t}$ test. Statistical significance was determined at $\mathrm{p}<0.05$.

\section{Result}

\subsection{Patients' Characteristics}

Table 1 displays the demographic and analytic traits of all patients. There were 22 boys $(73,33 \%)$ and 8 girls $(26.67 \%)$ and in term of right-hand dominance reported in 24 patients (80\%), and also 6 patients (20\%) were left-hand dominance. There was no representative change within both groups regarding age ( $\mathrm{p}=$ $0.8816)$, to sex $(\mathrm{p}=0.4265)$ and in term of hand dominance $(\mathrm{p}=0.3787)$.

\subsection{Changes in Posture Stability}

Mean test scores and SD for both groups are displayed in Table 2. The mean

Table 1. Patient's characteristics.

\begin{tabular}{cccc}
\hline Variables & Study group N = 15 & Control group N = 15 & P-value \\
\hline Age & $8.07 \pm 0.96$ & $7.20 \pm 1.26$ & 0.8816 \\
Sex N \% & $12(80 \%)$ & $10(66.67 \%)$ & \\
Boys & $3(20 \%)$ & $5(33.33 \%)$ & 0.4265 \\
Girls & & & \\
Hand dominance N \% & $13(86.67 \%)$ & $11(73.33 \%)$ & 0.3787 \\
Right & $2(13.33 \%)$ & $4(26.67 \%)$ & \\
Left & & & \\
\hline
\end{tabular}

Table 2. The average test of Posture stability level in both groups.

\begin{tabular}{cccc}
\hline Posture stability level & Study group & Control group & $\begin{array}{c}\text { P-value } \\
\text { (within groups) }\end{array}$ \\
\cline { 2 - 3 } & Mean \pm SD & Mean \pm SD & 0.9024 \\
Pre-treatment & $5.07 \pm 1.49$ & $5.00 \pm 1.46$ & 0.1118 \\
Post-treatment & $6.07 \pm 1.22$ & $5.27 \pm 1.44$ & 0.0044 \\
Improvement \% & $19.7 \%$ & $5.4 \%$ & \\
\hline
\end{tabular}


record of Posture stability level in the two groups at (pre- and post-treatment levels) was worthless ( $\mathrm{p}>0)$.

The average improvement of Posture stability level had a tendency to be extremely representatives improvement in the experimental group $(6.07 \pm 1.22$ versus $5.07 \pm 1.49, \mathrm{p}=0.0001)$ while worthless representatives in the control group (5.27 \pm 1.44 versus $5.00 \pm 1.46, \mathrm{p}=0.0406)$. The percentage of improvement of Posture stability level was $(19.7 \%)$ in the study group compared to the (5.4\%) in the control group.

\subsection{Changes in Coordination and Motor Control}

Mean test scores and SD for both groups are displayed in Table 3. The mean record of Coordination and motor control level in the two groups at (pre-and post-treatment) were worthless ( $\mathrm{p}>0.05)$. The average improvement of Coordination and motor control level had a tendency to be an extremely representative improvement in the study group $(5.33 \pm 1.40$ versus $4.47 \pm 1.51, \mathrm{p}=0.0001)$ while a representative in the control group $(4.73 \pm 1.03$ versus $4.40 \pm 0.99, \mathrm{p}=$ 0.0192). The percentage of improvement of Coordination and motor control level was $(19.24 \%)$ in the study group compared to the $(7.5 \%)$ in the control group.

\subsection{Changes in Jumping from Side to Side Scores}

Mean test scores and SD for both groups are displayed in Table 4. The mean record of Jumping from side to side scores in the two groups at (pre-and post-treatment) were worthless ( $p>0.05)$.

Table 3. The average test of coordination and motor control level in both groups.

\begin{tabular}{cccc}
\hline $\begin{array}{c}\text { Coordination and } \\
\text { motor control level }\end{array}$ & Study group & Control group & $\begin{array}{c}\text { P-value } \\
\text { (within groups) }\end{array}$ \\
\cline { 2 - 3 } Pre-treatment & Mean \pm SD & Mean \pm SD & 0.8869 \\
Post-treatment & $4.47 \pm 1.51$ & $4.40 \pm 0.99$ & 0.1919 \\
Improvement \% & $19.24 \%$ & $4.73 \pm 1.03$ & 0.0035 \\
P-value (within groups) & 0.0001 & $0.019 \%$ &
\end{tabular}

Table 4. The average test of jumping from side to side in both groups.

\begin{tabular}{cccc}
\hline $\begin{array}{c}\text { Jumping from side } \\
\text { to side }\end{array}$ & Study group & Control group & $\begin{array}{c}\text { P-value } \\
\text { (within groups) }\end{array}$ \\
\cline { 2 - 3 } Pre-treatment & Mean \pm SD & Mean \pm SD & 0.1855 \\
Post-treatment & $5.67 \pm 1.45$ & $6.33 \pm 1.23$ & 0.4594 \\
Improvement \% & $6.87 \pm 1.19$ & $6.53 \pm 1.25$ & 0.0005 \\
P-value (within groups) & $21.16 \%$ & $3.16 \%$ & \\
\hline
\end{tabular}


The average improvement of Jumping from side to side scores had a tendency to be extremely representatives improvement in the study group (6.87 \pm 1.19 versus $5.67 \pm 1.45, \mathrm{p}=0.0001)$ than in the control group ( $6.53 \pm 1.25$ versus 6.33 $\pm 1.23, \mathrm{p}=0.0824)$. The percentage of improvement of Jumping from side to side scores was $(21.16 \%)$ in the study group compared to the $(3.16 \%)$ in the control group.

\subsection{Changes in Motor Planning and Organization}

Mean test scores and SD for both groups are displayed in Table 5. The mean record of Motor planning and organization level in the two groups at (pre-and post-treatment) were worthless ( $p>0.05)$. The average improvement of Motor planning and organization level tended to be extremely representatives improvement in the study group $(7.47 \pm 1.51$ versus $6.67 \pm 0.63, \mathrm{p}=0.0001)$ while representatives improvement in the control group $(7.67 \pm 0.90$ versus $7.27 \pm$ $0.88, \mathrm{p}=0.0086)$. The percentage of improvement of Motor planning and organization level was $(12 \%)$ in the study group compared to the $(5.5 \%)$ in the control group.

\subsection{Changes in Grip Control Assessment}

Mean test scores and SD for both groups are displayed in Table 6. The mean record of Grip control assessment in the two groups at (pre-and post-treatment level) was representatives $(\mathrm{p}<0.05)$.

Table 5. The average test of motor planning and organization level in both groups.

\begin{tabular}{cccc}
\hline \multirow{2}{*}{$\begin{array}{c}\text { Motor planning and } \\
\text { organization level }\end{array}$} & Study group & Control group & $\begin{array}{c}\text { P-value } \\
\text { (within groups) }\end{array}$ \\
\cline { 2 - 3 } Pre-treatment & Mean \pm SD & Mean \pm SD & 0.2211 \\
Post-treatment & $7.47 \pm 1.51$ & $7.27 \pm 0.88$ & 0.6621 \\
Improvement \% & $12 \%$ & $5.5 \%$ & 0.0437 \\
P-value & 0.0001 & 0.0086 & \\
(within groups) & & & \\
\hline
\end{tabular}

Table 6. The average test of grip control assessment in both groups.

\begin{tabular}{cccc}
\hline \multirow{2}{*}{$\begin{array}{c}\text { Grip control } \\
\text { assessment }\end{array}$} & Study group & Control group & $\begin{array}{c}\text { P-value } \\
\text { (within groups) }\end{array}$ \\
\cline { 2 - 3 } Pre-treatment & Mean \pm SD & Mean \pm SD & 0.0411 \\
Post-treatment & $7.20 \pm 1.42$ & $6.13 \pm 1.30$ & 0.0070 \\
Improvement \% & $10.14 \%$ & $6.53 \pm 1.25$ & 0.3532 \\
P-value & 0.0012 & $6.5 \%$ & \\
(within groups) & & 0.0086 & \\
\hline
\end{tabular}


The average improvement of Grip control assessment had a tendency to be extremely representatives improvement in the study group $(7.93 \pm 1.39$ versus $7.20 \pm 1.42, \mathrm{p}=0.0012)$ than in the control group $(6.53 \pm 1.25$ versus $6.13 \pm 1.30$ $\mathrm{p}=0.0086)$. The percentage of improvement of Grip control assessment was $(10.14 \%)$ in the study group compared to the $(6.5 \%)$ in the control group.

\subsection{Kinesthesia Task Assessment}

Mean test scores and SD for both groups are displayed in Table 7. The mean record of Kinesthesia task assessment in the two groups at (pre-and post-treatment level) were worthless ( $p>0.05$ ). The average improvement of Kinesthesia task assessment had a tendency to be extremely representatives improvement in the study group $(14.80 \pm 0.77$ versus $13.2 \pm 1.26, \mathrm{p}=0.0001)$ than in the control group $(13.73 \pm 2.49$ versus $13.33 \pm 2.44 \mathrm{p}=0.0824)$. The percentage of $\mathrm{im}-$ provement of Kinesthesia task assessment was (12.12\%) in the study group compared to the $(3 \%)$ in the control group.

Table 7. The average test of kinesthesia task assessment in both groups.

\begin{tabular}{cccc}
\hline $\begin{array}{c}\text { Kinesthesia task } \\
\text { assessment }\end{array}$ & Study group & Control group & $\begin{array}{c}\text { P-value } \\
\text { (within groups) }\end{array}$ \\
\cline { 2 - 3 } Pre-treatment & Mean \pm SD & Mean \pm SD & 0.8523 \\
Post-treatment & $13.20 \pm 1.26$ & $13.33 \pm 2.44$ & 0.1246 \\
Improvement \% & $12.12 \%$ & $13.73 \pm 2.49$ & 0.0017 \\
P-value (within groups) & 0.0001 & 0.0824 & \\
\hline
\end{tabular}

\section{Discussion}

The results of the present study suggest that sensory integration therapy might be useful to enhance Posture stability, Coordination and motor control also Motor planning and organization in addition to exceed the control of grip ability and improve the awareness of body position and movement in Down syndrome children. Both groups showed increases of the Gross motor coordination in favor of study group in terms of postural stability $(6.07 \pm 1.22$ versus $5.07 \pm 1.49$, p $=0.0001)$ than in the control group $(5.27 \pm 1.44$ versus $5.00 \pm 1.46, \mathrm{p}=0.0406)$. And in favor of study group in term of Coordination and motor control level $(5.33 \pm 1.40$ versus $4.47 \pm 1.51, \mathrm{p}=0.0001)$ than the control group $(4.73 \pm 1.03$ versus $4.40 \pm 0.99, \mathrm{p}=0.0192)$. And in favor of study group in term of Jumping from side to side scores $(6.87 \pm 1.19$ versus $5.67 \pm 1.45, \mathrm{p}=0.0001)$ while insignificance in control group $(6.53 \pm 1.25$ versus $6.33 \pm 1.23, \mathrm{p}=0.0824)$. And in favor of study group in term of Motor planning and organization level (7.47 \pm 1.51 versus $6.67 \pm 0.63, \mathrm{p}=0.0001)$ than in the control group $(7.67 \pm 0.90$ versus $7.27 \pm 0.88, p=0.0086)$. Both groups showed increases of the grip control ability in favor of study group $(7.93 \pm 1.39$ versus $7.20 \pm 1.42, \mathrm{p}=0.0012)$ than in the 
control group $(6.53 \pm 1.25$ versus $6.13 \pm 1.30 \mathrm{p}=0.0086)$. Both groups showed increases of the Kinesthesia task assessment in favor of study group (14.80 \pm 0.77 versus $13.20 \pm 1.26, \mathrm{p}=0.0001)$ than in the control group $(13.73 \pm 2.49$ versus $13.33 \pm 2.44, \mathrm{p}=0.0824)$.

In normal children preprogramming and reaction time responses rely on reciprocal innervations or inhibition mechanism so improvement of this mechanism leading to improvement of motor abilities and decision making mechanism. These strategies are impaired in Down syndrome leading to clumsiness which means decreasing of movement reaction time and inability to respond rapidly to new stimulus. In fast movement, the down syndrome children cannot take a decision to correct the movement due to long reaction time and preprogramming defects leading to balance loss and fallen down. Inability of DS children to perform grip forces efficiently due to excessive forces produced (clumsiness) leading to wrong localization of object characteristics and release abilities [10].

Disorders related to DS include: -nervous system irregularities, impairment sensory feedback, delay of perceptual and cognitive skill, delay in speech and delay in gross and fine motor skills [23]-[29]. Slow reaction time, clumsy movement (lack of smoothness) and multijoint pointing tasks occurred due to impairment of initiation of movement as a response to external stimulus so it appeared as slowness movement also this occurred in a sequence of movement in which the Down syndrome children deal with each sequence of movement as a separate movement so increase in reaction time occur in compound movement [30] [31] [32] [33] [34].

As a result of delayed motor neuron myelination and decreased numbers of synapses of higher nervous centers neurons in Down syndrome released of primitive spinal pattern response over centrally coordinated pattern occurred [2] [35] [36]. An impaired spinal motor control mechanism is the main cause of lack of motor control in DS as clumsiness of movement with long reaction time and preprogramming delay [37] [38]. Delaying of cognitive skill in DS leading to impairment information process, delayed decision making, prolonged motor reaction time, delay of postural reaction and loss of anticipatory reaction and inability to accommodate sensory changes [2] [10] [39].

The DS children have chemical and mechanical changes leading to laxity of ligaments, hypotonia and abnormal movement pattern in which movement become slower with long reaction time, less smooth plus abnormal muscle co-contraction with the instability of the joints [40]-[45]. Posture instability in DS occurred due to hypotonia and laxity of ligaments as in Figure 3 \& Figure 4 which is obvious in hypermobility of the hip joints and presence of an abnormal co-contraction mechanism of agonist and antagonist of ankle and knee joints which decrease range of their motion so lower limbs become as inverse pendulum [40]. Abnormal movement pattern of DS has no relation with stretch reflex but mainly with abnormal feedback organization and feedforward command [46]. 


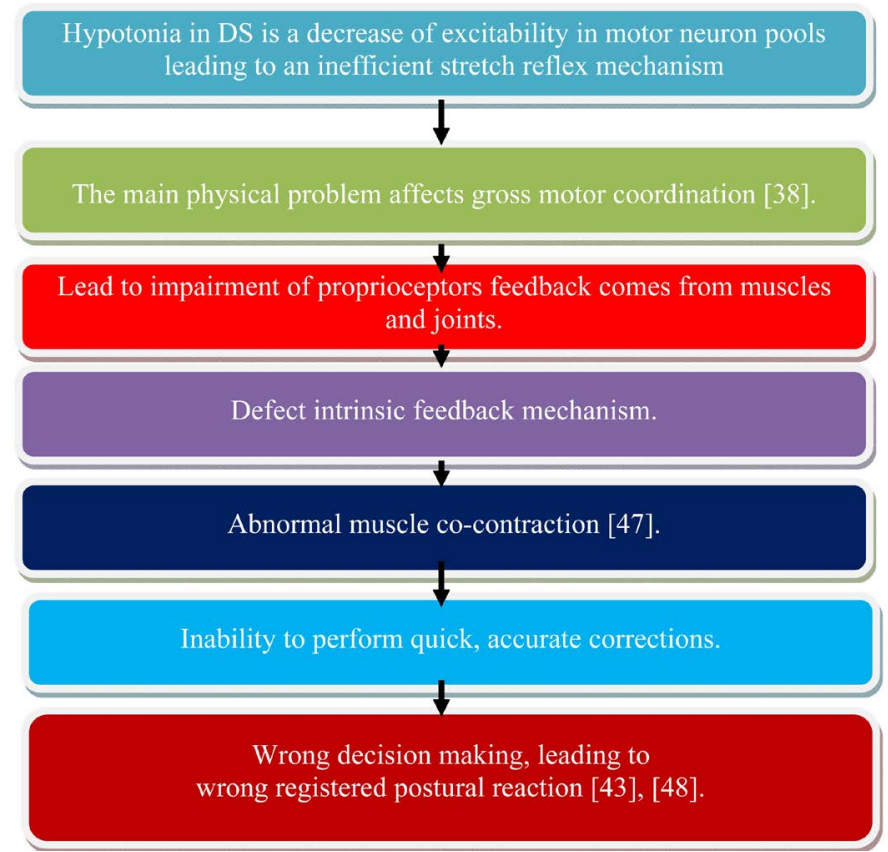

Figure 3. Complications of hypotonia in Down syndrome.

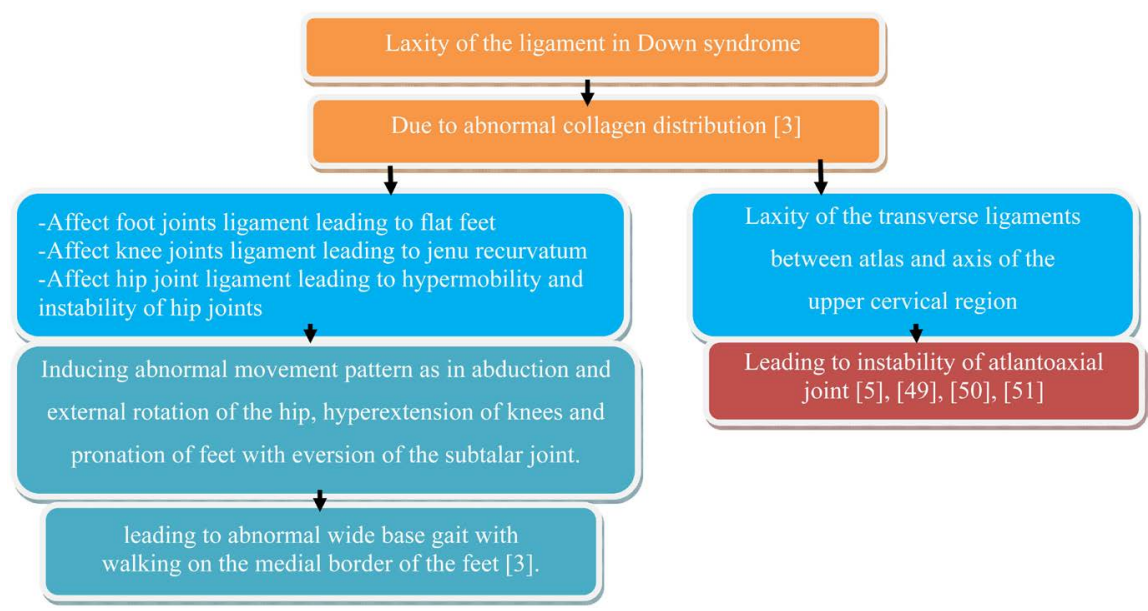

Figure 4. Complications of laxity ligaments in Down syndrome.

\section{Conclusion}

The addition of sensory integration therapy to specific physical therapy training is recommended in improving gross motor coordination and grip control, so this suggested approach may be used as a selective choice for gross motor and hand functions abilities in cases of Down syndrome.

\section{Acknowledgements}

I am grateful to my professor Emam El Negmy for his help and advices.

\section{Conflicts of Interest}

The main correspondence author declares that he has no conflict of interest. 


\section{References}

[1] Pangalos, C., Avramopoulos, D., Blouin, J., Raoul, O., Blois, M.C., Prieur, M., Schinzel, A.A., Gika, M., Abazis, D. and Antonarakis, S.E. (1994) Understanding the Mechanism(s) of Mosaic Trisomy 21 by Using DNA Polymorphism Analysis. American Journal of Human Genetics, 54, 473-481.

[2] Shumway-Cook, A. and Woollacott, M. (1985) Dynamics of Postural Control in the Child with Down Syndrome. Physical Therapy, 65, 1315-1322.

https://doi.org/10.1093/ptj/65.9.1315

[3] Shumway-Cook, A. and Woollacott, M.H. (2006) Motor Control: Translating Research into Clinical Practice. Wolters Kluwer Health, ¡Alphen aan den Rijn, Netherlands.

[4] Carvalho, R.L. and Vasconcelos, D.A. (2011) Motor Behavior in Down Syndrome: Atypical Sensorimotor Control. PUC Minas Gerais, Brazil.

https://www.intechopen.com

[5] Mancini, M.C., Silva, P.C., Gonçalves, S.C. and Martins, S.M. (2003) Comparison of the Functional Performance of Children with Down and Children with Normal Development at 2 and 5 Years of Age. Arquivos de Neuro-Psiquiatria, 61, 409-415. https://doi.org/10.1590/S0004-282X2003000300016

[6] Shields, N. and Dodd, K.A. (2004) A Systematic Review of the Effects of Exercise Programmes Designed to Improve Strength for People with Down Syndrome. Phys Therapy Reviews, 9, 109-115. https://doi.org/10.1179/108331904225005043

[7] Zickler, C.F., Morrow, J.D. and Bull, M.J. (1998) Infants with Down Syndrome: A Look at Temperament. Journal of Pediatric Health Care, 12, 111-117. https://doi.org/10.1016/S0891-5245(98)90240-1

[8] Caselli, M.C., Vicari, S., Longobardi, E., Lami, L., Pizzoli, C. and Stella, G. (1998) Gestures and Words in Early Development of Children with Down Syndrome. Journal of Speech, Language, and Hearing, 41, 1125-1135. https://doi.org/10.1044/jslhr.4105.1125

[9] Courage, M.L., Adams, R.J. and Hall, E.J. (1997) Contrast Sensitivity in Infants and Children with Down Syndrome. Vision Research, 37, 1545-1555. https://doi.org/10.1016/S0042-6989(96)00304-5

[10] Latash, M.L. (1992) Motor Control in Down Syndrome: The Role of Adaptation and Practice. Journal of Developmental and Physical Disabilities, 4, 227-261. https://doi.org/10.1007/BF01046967

[11] Case-Smith, J., Fisher, A.G. and Bauer, D. (1989) An Analysis of the Relationship between Proximal and Distal Motor Control. American Journal of Occupational Therapy, 43, 657-662. https://doi.org/10.5014/ajot.43.10.657

[12] Chiviacowsky, S., Wulf, G., Machado, C. and Rydberg, N. (2012) Self-Controlled Feedback Enhances Learning in Adults with Down Syndrome. Brazilian Journal of Physical Therapy, 16, 191-196. https://doi.org/10.1590/S1413-35552012005000019

[13] Kiphard, E.J. and Schilling, F. (2007) Body Coordination Test for Children 2, Revised and Supplemented Task. Beltz Test, Weinheim, Germany.

[14] Priosti, P.A., Assis, S.M., Cymrot, R., Vianna, D.L. and Caromano, F.A. (2013) Grip Strength and Manual Dexterity in Down Syndrome Children. Fisioterapia e Pesquisa, 20, No. 3. http://dx.doi.org/10.1590/S1809-29502013000300013

[15] Ayres, A.J. (1980) Southern California Sensory Integration Tests: Manual. Western Psychological Services, Los Angeles, CA.

[16] Winders, P.C. (2001) The Goal and Opportunity of Physical Therapy for Children 
with Down Syndrome. In: Cohen, W.I., Nadel, L. and Madnick, M.E., Eds., Down Syndrome: Visions for the 21 st Century, Wiley-Liss, Inc., Wilmington, Delaware.

[17] Williamson, G.G. and Anzalone, M.E. (2001) Sensory Systems and Sensory Integration. In: Sensory Integration and Self Regulation in Infants and Toddlers. Helping Very Young Children Interact with Their Environment, Zero to Three Publications, Washington DC.

[18] Kramer, P. and Hinojosa, J. (2007) Frames of Reference for Pedsiatric Occupational Therapy. 2nd Edition, Wolters Kluwer Co., Lippincott Williams and Wilkins, New York.

[19] Ayres, A.J. (1979) Sensory Integration and the Child. Western Psychological Services, Los Angeles, CA.

[20] Kelly, G. (1989) Vestibular Stimulation as a Form of Therapy. Physiotherapy, 75, 136-140. https://doi.org/10.1016/S0031-9406(10)62765-4

[21] Fisher, A.G. and Bundy, A.C. (1989) Vestibular Stimulation in the Intervention of Postural and Related Deficits. In: Payton, O.D., Ed., Manual of Physical Therapy, Churchill Livingstone, New York, Edinburgh.

[22] Blumenfeld, H. (2010) Neuroanatomy through Clinical Cases. 2nd Edition, Sinauer Associates, Sunderland, MA.

[23] Nichols, S., Jones, W., Roman, M.J., Wulfeck, B., Delis, D.C., Reilly, J., et al. (2004) Mechanisms of Verbal Memory Impairment in Four Neurodevelopment Disorders. Brain and Language, 88, 180-189. https://doi.org/10.1016/S0093-934X(03)00097-X

[24] Seung, H.K. and Chapman, R. (2004) Sentence Memory of Individuals with Down's Syndrome and Typically Developing Children. Journal of Intellectual Disability Research, 48, 160-171. https://doi.org/10.1111/j.1365-2788.2004.00526.x

[25] Tomporowski, P.D., Davis, C.L., Miller, P.H. and Naglieri, J.A. (2008) Exercise and Children'S Intelligence, Cognition, and Academic Achievement. Educational Psychology Review, 20, 111-131. https://doi.org/10.1007/s10648-007-9057-0

[26] Kennedy, E. and Flynn, M. (2003) Early Phonological Awareness and Reading Skills in Children with Down Syndrome. Down Syndrome Research and Practice, 8, 100-109. https://doi.org/10.3104/reports.136

[27] Laws, G. and Bishop, D.V. (2003) A Comparison of Language Abilities in Adolescents with Down Syndrome and Children with Specific Language Impairment. Journal of Speech, Language, and Hearing Research, 46, 1324-1339. https://doi.org/10.1044/1092-4388(2003/103)

[28] Connolly, B.H. and Michael, B.T. (1986) Performance of Retarded Children, with and without Down Syndrome, on the Bruininks Oseretsky Test of Motor Proficiency. Physical Therapy, 66, 344-348. https://doi.org/10.1093/ptj/66.3.344

[29] Torr, J., Strydom, A., Patti, P. and Jokinen, N. (2010) Aging in Down Syndrome: Morbidity and Mortality. Journal of Policy and Practice in Intellectual Disabilities, 7, 70-81.https://doi.org/10.1111/j.1741-1130.2010.00249.x

[30] Almeida, G.L., Corcos, D.M. and Latash, M.L. (1994) Practice and Transfer Effects during Fast Single-Joint Elbow Movements in Individuals with Down Syndrome. Physical Therapy, 74, 1000-1012. https://doi.org/10.1093/ptj/74.11.1000

[31] Aruin, A.S. and Almeida, G.L. (1997) A Coactivation Strategy in Anticipatory Postural Adjustments in Person with Down Syndrome. Motor Control, 1, 178-191. https://doi.org/10.1123/mcj.1.2.178

[32] Haley, S.M. (1986) Postural Reactions in Infants with Down Syndrome: Relationship to Motor Milestone Development and Age. Physical Therapy, 66, 17-22. 
https://doi.org/10.1093/ptj/66.1.17

[33] Galli, M., Rigoldi, C., Mainardi, L., Tenore, N., Onorati, P. and Albertini, G. (2007) Postural Control in Patients with Down Syndrome. Disability and Rehabilitation, 14, S8. https://doi.org/10.1016/S1353-8020(08)70090-7

[34] Vuillerme, N., Marin, L. and Debu, B. (2001) Assessment of Static Postural Control in Teenagers with Down Syndrome. Adapted Physical Activity Quarterly, 18, 417-433. https://doi.org/10.1123/apaq.18.4.417

[35] Haley, S.M. (1987) The Sequence of Development of Postural Reactions by Infants with Down Syndrome. Developmental Medicine and Child Neurology, 29, 674-679. https://doi.org/10.1111/j.1469-8749.1987.tb08510.x

[36] Woollacott, M.H. and Cook, A.S. (1986) The Development of the Postural and Voluntary Motor Control Systems in Down's Syndrome Children. In: Wade, M.G., Ed., Motor Skills Acquisition of the Mentally Handicapped: Issues in Research and Training, Elsevier Science, North Holland, 45-71. https://doi.org/10.1016/S0166-4115(08)61157-7

[37] Parker, A.W., Parker, A.W. and Bronks, R.B. (1980) Gait of Children with Down Syndrome. Arch. Phys.s, R. B. Gait of Children with Down Syndrome. Arch. Phys. Med. Rehab, 61, 345-351.

[38] Gilman, S., Bloedel, J.R. and Lechtenberg, R. (1981) Disorders of the Cerebellum. F.A. Davis Company, Philadelphia, PA.

[39] Latash, M.L. and Anson, G.J. (1996) What Are "Normal Movements" in Atypical Population? Behavioral and Brain Science, 19, 55-68. https://doi.org/10.1017/S0140525X00041467

[40] Rigoldi, C., Galli, M. and Albertini, G. (2011) Gait Development during Lifespan in Subjects with Down Syndrome. Research in Developmental Disabilities, 32, 158-163. https://doi.org/10.1016/j.ridd.2010.09.009

[41] Rigoldi, C., Galli, M., Mainardi, L., Crivellini, M. and Albertini, G. (2011) Postural Control in Children, Teenagers, and Adults with Down Syndrome. Research in Developmental Disabilities, 32, 170-175. https://doi.org/10.1016/j.ridd.2010.09.007

[42] Galli, M., Cimolin, V., Patti, P., Ferrario, D., Heaney, G., Albertini, G. and Freedland, R. (2010) Quantifying Established Clinical Assessment Measures Using 3D-Movement Analysis in Individuals with Down Syndrome. Disability \& Rehabilitation, 32, 1768-1774. https://doi.org/10.3109/09638281003734367

[43] Aruin, A.S., Almeida, G.L. and Latash, M.L. (1996) Organization of a Simple Two-Joint Synergy in Individuals with Down Syndrome. American Journal of Mental Retardation, 101, 256-268.

[44] Mahan, K.T., Diamond, E. and Brown, D. (1983) Podiatric Profile of the Down's Syndrome Individual. Journal of the American Podiatric Medical Association, 73, 173-179. https://doi.org/10.7547/87507315-73-4-173

[45] Lauteslager, P.E.M., Vermeer, A. and Helders, P.J.M. (1998) Disturbances in the Motor Behavior of Children with Down's Syndrome: The Need for a Theoretical Framework. Physiotherapy, 84, 5-13. https://doi.org/10.1016/S0031-9406(05)65896-8

[46] Davis, W.E. and Kelso, J.A. (1982) Analysis of "Invariant Characteristics" in the Motor Control of Down's Syndrome and Normal Subjects. Journal of Motor Behavior, 14, 194-211. https://doi.org/10.1080/00222895.1982.10735273

[47] Dyer, S., Gunn, P., Rauh, H. and Berry, P. (1990) Motor Development in Down Syndrome Children: An Analysis of the Motor Scale of the Bayley Scales of Infant 
Development. Motor Development, Adapted Physical Activity and Mental Retardation, 30, 7-20. https://doi.org/10.1159/000418576

[48] Latash, M.L., Yarrow, K. and Rothwell, J.C. (2003) Changes in Finger Coordination and Responses to Single Pulse TMS of Motor Cortex during the Practice of a Multi-Finger Force Production Task. Experimental Brain Research, 151, 60-71. https://doi.org/10.1007/s00221-003-1480-y

[49] Livingstone, B. and Hirst, P. (1986) Orthopedic Disorders in School Children with Down's Syndrome with Special Reference to the Incidence of Joint Laxity. Clinical Orthopedics and Related Research, 207, 74-76. https://doi.org/10.1097/00003086-198606000-00013

[50] Gunasingham, V. and Akuffo, E.O. (1988) The Significance of Atlanto-Axial Instability in Dowsn's Syndrome. Journal of Mental Deficiency Research, 32, 501-505. https://doi.org/10.1111/j.1365-2788.1988.tb01443.x

[51] Pueschel, S.M., Tingey, C., Rynders, J.E., Crocker, A.C. and Crutcher, D.M. (1987) New Perspectives a Down Syndrome. Brookes Publishing, Baltimore, MD. 